\title{
Avaliação de coliformes, Salmonella sp., bolores e leveduras em superfícies de latas de refrigerante
}

\author{
Evaluation of coliforms, Salmonella sp., molds and yeasts on soda cans surfaces \\ Evaluación de coliformes, Salmonella sp., mohos y levaduras en superficies de latas de refresco
}

Recebido: 02/09/2021 | Revisado: 10/09/2021 | Aceito: 11/09/2021 | Publicado: 13/09/2021

Lidiane Pinto de Mendonça ORCID: https://orcid.org/0000-0001-5597-2446 Universidade Federal Rural do Semi-Árido, Brasil E-mail: lidiane.mendonca@outlook.com

Renata Cristina Borges da Silva Macedo ORCID: https://orcid.org/0000-0003-4012-0659 Universidade Federal Rural do Semi-Árido, Brasil E-mail: renata.bsmacedo@gmail.com

Elisandra Cibely Cabral de Melo ORCID: https://orcid.org/0000-0002-2157-4535 Universidade Federal de Pernambuco, Brasil E-mail: elisandra-cabral8@hotmail.com

Flávio Estefferson de Oliveira Santana ORCID: https://orcid.org/0000-0002-4675-2713 Universidade Federal Rural do Semi-Árido, Brasil E-mail: flavioestefferson@hotmail.com

Rosueti Diógenes de Oliveira Filho ORCID: https://orcid.org/0000-0003-4944-2080 Faculdade Nova Esperança de Mossoró, Brasil E-mail: fi_diorgenes@hotmail.com

Olicélia Magna Tunico de Oliveira ORCID: https://orcid.org/0000-0001-9652-5116 Faculdade Nova Esperança de Mossoró, Brasil E-mail: olicelia.olvr@gmail.com

Ana Carla Diógenes Suassuna Bezerra ORCID: https://orcid.org/0000-0002-1039-5187 Universidade Federal Rural do Semi-Árido, Brasil E-mail: anacarla@ufersa.edu.br

Karoline Mikaelle de Paiva Soares ORCID: https://orcid.org/0000-0003-1578-3733 Universidade Federal Rural do Semi-Árido, Brasil E-mail: karolinesoares@ufersa.edu.br

\begin{abstract}
Resumo
Refrigerante é uma mistura gaseificada altamente consumida devido à praticidade e aceitação pelos consumidores. Contudo, o consumo desta bebida que, por muitas vezes se dá diretamente na embalagem, torna o produto uma possível via de proliferação de micro-organismos, trazendo riscos de contaminação e transmissão de Doenças Transmitidas por Alimentos. Assim, o presente estudo teve por objetivo avaliar a qualidade microbiológica da superfície de latas de refrigerantes. Foram avaliadas 20 amostras, sendo dez coletadas de vendedores ambulantes e dez obtidas em supermercados na cidade de Mossoró, Rio Grande do Norte, com investigação da possível presença de coliformes, Salmonella sp., bolores e leveduras. Os resultados mostraram que $75 \%$ das amostras apresentaram contaminação por coliformes totais, $10 \%$ apresentaram coliformes termotolerantes, $5 \%$ continham Salmonella sp. e que $100 \%$ tinham contaminação superficial de bolores e leveduras. As superfícies das latas de refrigerante apresentaram condições higiênico-sanitárias insatisfatórias de comercialização e consumo, sendo necessária a execução de boas práticas de manipulação visando minimizar os riscos de transmissão de Doenças Transmitidas por Alimentos.
\end{abstract}

Palavras-chave: Doenças transmitidas por alimentos; Micro-organismos patogênicos; Bebida gaseificada.

\begin{abstract}
Soda is a highly consumed aerated mixture due to its practicality and consumer acceptance. However, the consumption of this drink, which often takes place directly on the packaging, makes the product a possible way of proliferation of microorganisms, bringing risks of contamination and transmission of Foodborne Diseases. Thus, the present study aimed to evaluate the microbiological quality of the surface of soda cans. Twenty samples were
\end{abstract}


evaluated, being ten collected from street vendors and ten obtained in supermarkets in the city of Mossoró, Rio Grande do Norte, with investigation of the possible presence of coliforms, Salmonella sp., molds and yeasts. The results showed that $75 \%$ of the samples were contaminated by total coliforms, $10 \%$ had thermotolerant coliforms, $5 \%$ contained Salmonella sp. and that $100 \%$ had surface contamination from molds and yeasts. The surfaces of the soda cans presented unsatisfactory hygienic and sanitary conditions for marketing and consumption, requiring the implementation of good handling practices in order to minimize the risk of transmission of Foodborne Diseases.

Keywords: Foodborne diseases; Pathogenic microorganisms; Carbonated drink.

\section{Resumen}

El refresco es una mezcla aireada muy consumida debido a su practicidad y aceptación por parte del consumidor. Sin embargo, el consumo de esta bebida, que muchas veces se realiza directamente sobre el envase, convierte al producto en una posible vía de proliferación de microorganismos, trayendo riesgos de contaminación y transmisión de Enfermedades Transmitidas por Alimentos. Así, el presente estudio tuvo como objetivo evaluar la calidad microbiológica de la superficie de las latas de refresco. Se evaluaron veinte muestras, diez recolectadas de vendedores ambulantes y diez obtenidas de supermercados de la ciudad de Mossoró, Rio Grande do Norte, con investigación de la posible presencia de coliformes, Salmonella sp., Mohos y levaduras. Los resultados mostraron que el $75 \%$ de las muestras estaban contaminadas por coliformes totales, el 10\% tenían coliformes termotolerantes, el 5\% contenía Salmonella sp. y que el $100 \%$ tenía contaminación superficial por mohos y levaduras. Las superficies de las latas de refresco presentaban condiciones higiénico-sanitarias insatisfactorias para su comercialización y consumo, requiriendo la implementación de buenas prácticas de manejo para minimizar el riesgo de transmisión de Enfermedades Transmitidas por Alimentos.

Palabras clave: Enfermedades transmitidas por alimentos; Microorganismos patógenos; Bebida carbonatada.

\section{Introdução}

Com a inserção da mulher no mercado de trabalho e o fácil acesso aos alimentos prontos, ocorreu um crescimento no consumo diário das refeições fora de casa. Alimentos que estão disponíveis de forma rápida e prática muitas vezes não são preparados e comercializados com os devidos cuidados sanitários, tornando-os assim uma possível fonte de contaminação e transmissão de Doenças Transmitidas por Alimentos (Moura et al., 2020; Macedo et al., 2021).

Com isso, cria-se um gasto a mais, por essas refeições as vezes apresentarem um valor alto de faturamento, como também um risco para a saúde dos consumidores, caso esses alimentos não sejam manuseados e/ou conservados dentro das boas práticas de fabricação (Aguiar; Costa, 2018). É comum a ingestão de bebidas em estabelecimento externos, entre elas, os refrigerantes. Os refrigerantes são bebidas gaseificadas, obtidas pela dissolução em água potável, de suco ou extrato vegetal de sua origem, adicionada de açúcares (Brasil, 1998).

O consumo desse produto vem sendo um hábito na vida dos brasileiros, seja em seus lares ou em diversos tipos de comércios como bares, lanchonetes, festas e/ou restaurantes. No entanto, há uma preocupação na forma de consumo dessa bebida, comercializadas também em latas, uma vez que muitas pessoas tem o hábito de fazer esse consumo na própria embalagem sem nenhum tipo de higienização prévia (Silverio et al., 2010). Esse hábito pode representar um risco à saúde dos consumidores, caso a embalagem não tenha sido manipulada de forma correta durante a sua comercialização, podendo ser um veículo de transmissão de micro-organismos (Mendonça et al., 2020a).

Uma forma de contaminação atribuída a esse tipo de produto, ocorre devido à embalagem entrar em contato direto com mãos e equipamentos dos vendedores, que muitas vezes não tem consciência das boas práticas de higiene. Consequentemente essa bebida acaba sendo exposta a diversos tipos de contaminação, sendo um veículo de transmissão microbiológica. Uma forma de amenizar essa problemática, é a adoção de medidas higiênico-sanitárias adequadas de manipulação durante a sua comercialização (Mata; Barcelos; Martins, 2010; Souza et al., 2020).

Vale ressaltar que a resolução - RDC n 216, de 15 de setembro de 2004, que dispõe sobre Regulamento Técnico de Boas Práticas para Serviços de Alimentação, é um importante instrumento na avalição das condições higiênico-sanitárias nos 
estabelecimentos, incluindo o mercado ambulante, este, aborda questões relevantes para a contribuição de um alimento seguro ao consumo humano (Brasil, 2001; Sá et al., 2010).

Desse modo, o objetivo da presente pesquisa foi realizar a avaliação microbiológica da superfície de latas de refrigerantes comercializadas por vendedores ambulantes e supermercados no município de Mossoró, Rio Grande do Norte.

\section{Metodologia}

Foram coletadas 20 amostras de latas de refrigerantes, sendo dez amostras adquiridas através de vendedores ambulantes (escolhidos, aleatoriamente, sendo utilizado como único critério de inclusão a comercialização de bebidas no interior de caixas de isopor) e dez amostras coletadas em supermercados no município de Mossoró, Rio Grande do Norte. Durante a coleta não houve nenhum tipo de contato com a região superior das latas, sendo que todas as amostras coletadas foram acondicionadas individualmente em sacos plásticos estéreis, fechadas, identificadas e acondicionadas em caixas isotérmicas previamente sanitizadas, minimizando o risco de interferência externa (Figura 1a). Após coleta, as amostras foram transportadas imediatamente ao laboratório para a realização das análises microbiológicas.

As análises microbiológicas foram realizadas segundo o Compendium of Methods for the Microbiological Examination of Foods da American Public Health Association (Apha, 2001), constando de pesquisa de Salmonella sp., determinação do Número Mais Provável (NMP/mL) de coliformes totais e termotolerantes e contagem de bolores e leveduras. As análises foram realizadas de forma asséptica em cabine de fluxo laminar previamente esterilizada com radiação ultravioleta durante 20 minutos.

A avaliação microbiológica foi realizada através de esfregaço com auxílio de $s w a b$ (cotonete) estéril na superfície das latas (Figura 1b). A extensão do esfregaço considerou toda superfície de probabilidade de contato com a boca do consumidor. Após este procedimento, o swab foi imerso em água peptonada tamponada para a obtenção da diluição $10^{-1}$.

Figura 1. a) Lata embalada em saco estéril. b) Realização do esfregaço na superfície da lata.
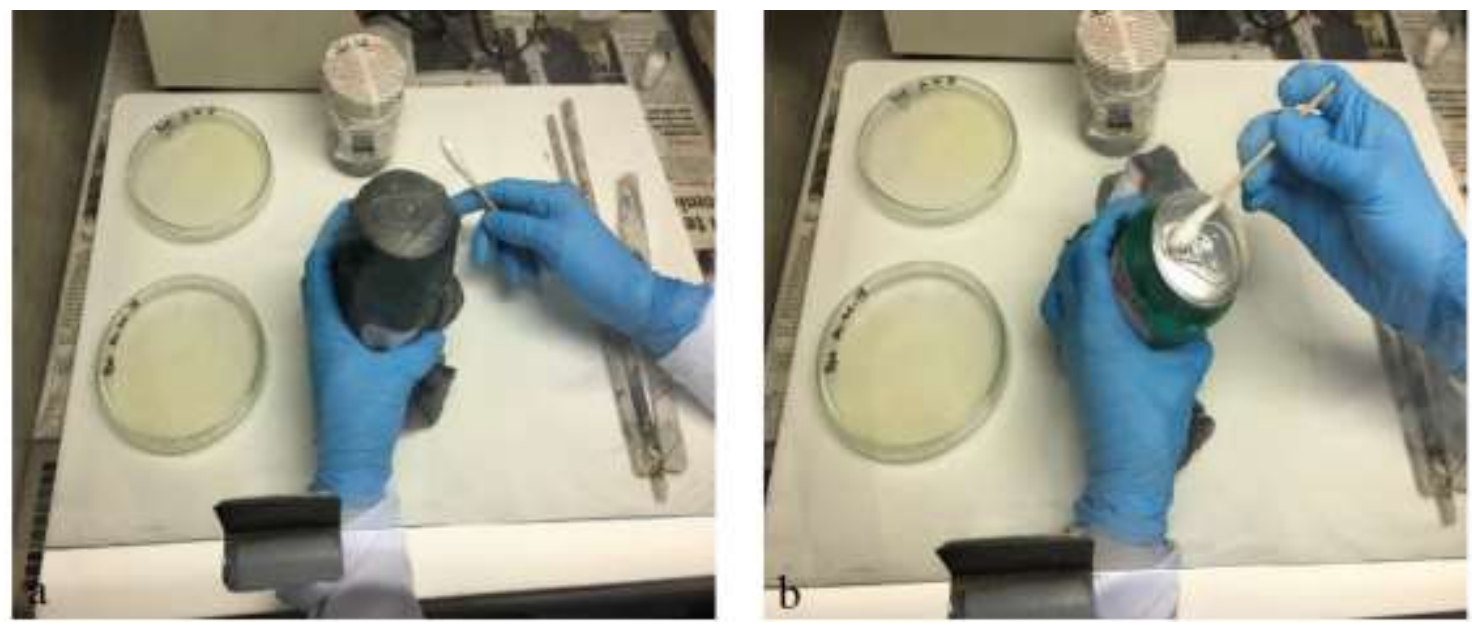

Fonte: Autores (2021).

Para pesquisa de Salmonella sp., as amostras foram incubadas a partir da diluição um, a $36^{\circ} \mathrm{C}$ durante 24 horas. Posteriormente, as amostras foram inseridas em tubos de caldo tetrationato, caldo selenito cistina e caldo Rappaport Vassiliadis e incubadas em banho-maria a $41{ }^{\circ} \mathrm{C}$ durante 24 horas. Por seguinte, foi realizado o plaqueamento fazendo estrias com alça microbiológica nos meios ágares de EMB e Salmonella Shigella, onde as placas foram incubadas a $36^{\circ} \mathrm{C} \pm 1$ por 24 horas. Para confirmação de Salmonella sp, foram realizadas provas bioquímicas observando-se a ocorrência de reações típicas desse 
micro-organismo, tais como: descarboxilação da lisina, de fermentação da lactose e/ou sacarose e produção de ácido sulfídrico, no ágar LIA (Lysine Iron Agar) e TSI (Triple Sugar Iron), como também o teste da urease.

Para determinar a presença de coliformes totais, utilizou-se um $\mathrm{mL}$ de cada amostra em tubos contendo caldo verde brilhante $2 \%$, em seguida foram inoculadas em banho-maria a $36^{\circ} \mathrm{C}$ por um período de 48 horas, sendo confirmada a presença da mesma pela formação de gás no tubo de Durhan, ou em efervescência quando agitado. Os tubos confirmados pela presença de coliformes totais, foram imediatamente transferidos para o caldo Escherichia coli (E.C.) e inoculados à $45^{\circ} \mathrm{C}$ por 48 horas em banho-maria, onde também se avaliou a formação de gás no tubo de Durhan ou efervescência quando agitado. Os resultados para coliformes totais e termotolerantes foram expressos em NMP/g.

A contagem de bolores e leveduras foi realizada em duplicata utilizando a técnica de plaqueamento em superfície, sendo as amostras diluídas inoculadas $(1 \mathrm{~mL})$ em placas contendo meio BDA (Ágar Batata Dextrose) e espalhado com o auxílio da alça de Drigalski estéril. Em seguida foi feita a i ncubação das placas em estufa BOD (Biochemical Oxygen Demand) com temperatura controlada de $25^{\circ} \mathrm{C}$ durante sete dias.

\section{Resultados e Discussão}

Das dez amostras que foram coletadas por vendedores ambulantes, seis amostras (60\%) apresentaram crescimento de coliformes em valores variando de 9,2 a $1100 \mathrm{NMP} / \mathrm{mL}$. Dentre estas, verificou-se que duas amostras (20\%), apresentaram contaminação por coliformes termotolerantes, com valores de $240 \mathrm{NMP} / \mathrm{mL}$ e $1100 \mathrm{NMP} / \mathrm{mL}$. Para as latas de refrigerantes adquiridas em supermercados, constatou-se a contaminação por coliformes totais em sete amostras $(70 \%)$, com valores entre 3,6 e $460 \mathrm{NMP} / \mathrm{mL}$. Os resultados obtidos para o perfil microbiológico de superfícies de latas de refrigerantes comercializadas por vendedores ambulantes e supermercados no município de Mossoró-RN estão descritos na Tabela 1.

Tabela 1. Número de amostras de latas de refrigerantes com valores relevantes quanto às avaliações microbiológicas.

\begin{tabular}{cccccc}
\hline $\begin{array}{c}\text { Forma de } \\
\text { comercialização }\end{array}$ & $\begin{array}{c}\text { Coliformes } \\
\text { totais }(\%)\end{array}$ & $\begin{array}{c}\text { Coliformes } \\
\text { termotolerantes } \\
(\%)\end{array}$ & $\begin{array}{c}\text { Salmonella } \\
\text { sp. }(\%)\end{array}$ & $\begin{array}{c}\text { Bolores e } \\
\text { leveduras } \\
(\%)\end{array}$ & $\begin{array}{c}\text { Total de } \\
\text { amostras }\end{array}$ \\
\hline Vendedores ambulantes & $6(60)$ & $2(20)$ & $1(10)$ & $10(100)$ & 10 \\
Supermercados & $7(70)$ & 0 & 0 & $10(100)$ & 10 \\
Total & $15(75)$ & $2(10)$ & $1(5)$ & $20(100)$ & 20 \\
\hline
\end{tabular}

Fonte: Autores (2021).

Apesar de que a Resolução RDC nº 12 de 02 de janeiro de 2001 (Brasil, 2001) não preconizar valores referentes à quantidade micro-organismos coliformes totais na superfície de latas de refrigerantes, a presença de coliformes em alimentos indica que os mesmos foram submetidos a condições higiênico sanitárias inadequadas, o que pode ocasionar riscos ao consumidor (Franco; Landgraf, 2008; Silva et al., 2021). Com base nisso, as superfícies de latas avaliadas nessa pesquisa, podem ter sido manipuladas e/ou conservadas de forma inadequada. Na pesquisa realizada por Pereira (2016), analisou a microbiologia da superfície de 36 latas de bebidas comercializadas em Patos na Paraíba, no qual verificou 69,44\% (25 amostras) confirmaram a presença de coliformes totais e termotolerantes. Esse estudo analisou também uma amostra controle devidamente higienizada com água e sabão, verificando que a mesma não apresentou crescimento de micro-organismos. Em estudos realizados por Melo et al. (2012), verificou-se a presença de coliformes em 52,08\% (25/48) das latas examinadas. 
Ao realizar-se a pesquisa de Salmonella sp., constatou-se que apenas uma amostra (5\% do total de amostras avaliadas para vendedores ambulantes e supermercados) mostrou-se positiva para esse micro-organismo. A Salmonella sp. é um dos micro-organismos mais envolvidos em doenças de origem alimentar, causando dores abdominais, diarreia, febre e vômito, com isso, a presença em alimentos significa que esta passou por algum processo de contaminação (Santos et al., 2020; Mendonça et al., 2020b). Neste contexto, verifica-se que as latas de refrigerantes estão propícias a contaminação, por falta de higiene na manipulação ou armazenamento, visto que uma das amostras analisadas se mostrou positiva para esse patógeno.

Mata, Barcelos e Martins (2010) analisaram 32 amostras de latas de refrigerantes e cervejas coletadas em supermercados, restaurantes, quiosques e comércio ambulante, na cidade de Vila-Velha, Espírito Santo, no qual todas as amostras analisadas mostraram-se negativas quando submetidas a pesquisa de Salmonella sp.

No que se diz respeito as análises de bolores e leveduras, $100 \%$ das amostras (tanto para a comercialização através de ambulantes quanto para a venda em supermercados) apresentaram contaminação para esse tipo de micro-organismo, sendo que

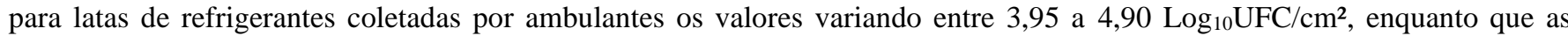
amostras adquiridas em supermercados apresentaram um crescimento microbiano de 2,02 a 3,72 $\log _{10} \mathrm{UFC} / \mathrm{g}$.

Os bolores e leveduras são pertencentes ao grupo dos fungos, os bolores são em sua maioria aeróbios, nisto, há a explicação pelo qual seu crescimento em alimentos se dá a superfície em contato com o ar. As leveduras requerem menos umidade do que os bolores, multiplicando-se melhor quando estão em aerobiose sendo que os açúcares são sua melhor fonte de energia. Os bolores e leveduras são os principais agentes que deterioram os alimentos quando eles oferecem condições desejáveis a sua multiplicação, como também podem produzir toxinas que prejudicam a saúde humana. (Franco; Landgraf, 2008; Carmo et al., 2020).

Melo, Ribeiro e Rauecker (2012), em suas pesquisas, analisaram 48 amostras de bebidas em latas comercializadas em Goiânia, no qual 78,8\% (34 amostras) mostraram contaminação por fungos com valores variando entre 1 a 612 Log ${ }_{10}$ UFC/cm².

Muitos vendedores não se preocupam e não se adequam corretamente conforme as boas práticas orientam. Sabe-se que o uso do uniforme limpo, unhas cortadas, ausência de bigode e barba como também cabelos presos, são medidas essenciais na manutenção de um alimento seguro ao consumo humano, já que as faltas desses procedimentos básicos podem acarretar contaminações física, química e biológica.

As mãos dos manipuladores são meios propícios à veiculação de micro-organismos e, por essa razão, a manipulação do dinheiro é um agravante a esse risco de contaminação (Maia; Oliveira; Oliveira, 2010). A falta de utensílios básicos de higienização, por parte do vendedor ao segurar o refrigerante, como por exemplo o guardanapo, pode facilitar a contaminação da lata, caso o mesmo toque no local onde o consumidor põe a boca ao ingerir a bebida. Associado a essa problemática, o não fornecimento de copos pode potencializar o risco do consumo na própria embalagem. Dessa forma, é de grande importância a disposição de guardanapos e copos pelo vendedor ambulante, facilitando sua utilização por parte dos consumidores (Mata; Barcelos; Martins, 2010) e diminuindo os riscos de veiculação de micro-organismos através das latas (Siverio et al., 2010).

Segundo Figueiredo, Castro e Calvet (2018), a higiene do local de venda de alimentos deve ser realizada de forma precisa, dando ao ambiente um lugar sem riscos de contaminações, sendo de extrema importância que a lixeira seja disposta com pedal, para que o manipulador não tenha que tocar na superfície contaminada ao manusear os produtos, evitando assim contaminação cruzada e riscos à saúde do consumidor. Esses autores avaliaram três boxes de vendas de pescado em Timon/MA, eles verificaram que $100 \%$ deles estavam irregulares no quesito higiene do local, equipamento e utensílios, havendo grande risco de contaminação microbiológica do pescado (Figueiredo; Castro; Calvet, 2018).

Sá et al. (2010), ao analisarem as condições higiênico-sanitárias do comércio ambulante de alimentos prontos para consumo na cidade de Uberlândia, MG, verificaram inadequações em práticas de higienização. Esses autores detectaram falhas nas instalações, nos recipientes, utensílios e nos manipuladores. 


\section{Conclusão}

A comercialização de latas de refrigerante, seja por ambulantes ou nos supermercados, apresentou-se condições higiênico sanitárias inadequadas relacionadas aos quesitos de higiene do manipulador, do local e dos equipamentos e utensílios. Logo, há necessidade de melhores condições higiênico-sanitárias dos vendedores, como também a higienização prévia ao consumo por parte dos clientes a fim de evitar a proliferação de Doenças Transmitidas por Alimentos através da ingestão de micro-organismos no ato do consumo das bebidas.

\section{Referências}

Aguiar, I. W. O. \& Costa, A. M. M. D. (2018). Práticas higiênico-sanitárias de vendedores ambulantes em um campus universitário em Fortaleza/CE. Higiene Alimentar, 32 (278-279), 52-57.

Apha (2010). Compendium of methods for the microbiological examination of foods. CONIC SEMESP.

Brasil (1998). Regulamentos Técnicos para Fixação dos Padrões de Identidade e Qualidade, para refresco, refrigerante, preparado ou concentrado líquido para refresco ou refrigerante, preparado sólido para refresco, xarope e chá pronto para o consumo. Diário Oficial [da] República Federativa do Brasil.

Brasil (2001). Resolução no 12, de 02 de janeiro de 2001, Regulamento Técnico sobre Padrões Microbiológicos para Alimentos. Diário Oficial [da] República Federativa do Brasil.

Carmo, M. G., Macedo, R. C. B. S., Rabelo, J. L. G. et al. (2020). Pesquisa de micro-organismos, parasitos e sujidades em coxinhas comercializadas por ambulantes. Research, Society and Development, 9 (12), e35291210737.

Figueiredo, L. A. S. F., Castro, S. S. V. \& Calvet, R. M. (2018). Aspecto higiênico sanitários dos boxes de comercialização de pescado no mercado municipal José Emídio em Timon/MA. Higiene Alimentar, 32 (278-279), 63-67.

Franco, B. D. G. \& Landgraf, M. (2008). Microbiologia dos alimentos. Atheneu.

Macedo, R. C. B. S., Rebouças, C. K. O., Melo, E. C. C. et al. (2021). Avaliação da qualidade físico-química e microbiológica de salsichas do tipo hot dog na cidade de Mossoró, Rio Grande do Norte, Brasil. Research, Society and Development, 10 (11), e118101119195.

Maia, L. F., Oliveira, M. T. \& Oliveira, A. F. (2010). Condições higiênico-sanitárias, qualidade microbiológica e teste de susceptibilidade antimicrobiana de cepas isoladas de sanduíches comercializados por ambulantes. Rev. Inst. Adolfo Lutz, 69 (4), 489-496.

Mata, C. A., Barcelos, F. A. \& Martins, J. D. L. (2010). Pesquisa de Escherichia coli, Salmonella sp, Staphylococcus coagulase positiva, bolores e leveduras em superfícies de latas de refrigerante e cerveja. Higiene Alimentar, 24 (190-191), 122-127.

Melo, C. L., Ribeiro, R. S. \& Rauecker, U. (2012). Avaliação da contaminação microbiana de latas de cerveja comercializadas na festa de trindade -GO. https://unigy.edu.br/repositorio/2012-2/Farmacia/AVALIA\%C3\%87\%C3\%83O\%20DA\%20CONTAMINA\%C3\%87\%C3\%83O \%20MICROBIANA\%20D E\%20LATAS\%20DE\%20CERVEJA\%20COMERCIALIZADAS\%20NA\%20FESTA\%20DE\%20TRINDADE\%20-\%20GO.pdf.

Mendonça, L. P., Costa, M. G. A., Macedo, R. C. B. S. et al. (2020a). Doenças emergentes de origem alimentar: uma revisão. Revista Brasileira De Educação E Saúde, 10 (3), 1-6.

Mendonça, L. P., Melo, E. C. C., Macedo, R. C. B. S. et al. (2020b). Caracterização microbiológica, físico-química e de rotulagem de águas de coco envasadas. Research, Society and Development, 9 (8), e273985299.

Moura, D. A., Ramos, G. L. P. A., Lima, R. A. et al. (2020). Avaliação microbiológica do mate vendido em praias da cidade do Rio de Janeiro. Alimentos: Ciência, Tecnologia e Meio Ambiente, 1 (4), 119-138.

Pereira, J. S. (2016). Avaliação microbiológica da superfície de latas de bebidas comercializadas em Patos, Paraíba. Universidade Federal de Campina Grande.

Sá, M. A. R., Paiva, D. S., Freitas, E. M et al. (2010). Condições higiênico-sanitárias do comércio ambulante de alimentos prontos para consumo, no entorno do hospital de clínicas de Uberlândia, MG. Higiene alimentar, 24 (190-191), 59-64.

Santos, K. P. O., Faria, A. C. S. R., Silva, D. P. A. et al. (2020). Salmonella spp. como agente causal em Doenças Transmitidas por Alimentos e sua importância na saúde pública: Revisão. PUBVET, 14 (10), 1-9.

Silva, G. P., Macedo, R. C. B. S., Santana, F. E. O. et al. (2021). Pesquisa de micro-organismos indicadores de qualidade higiênico-sanitária em sorvete expresso na Cidade de Mossoró, Rio Grande do Norte, Brasil. Research, Society and Development, 10 (11), e345101119478.

Silverio, A. S. P., Silva, D., Saenz, C. C. B. et al. (2010). Análise microbiológica para determinar a contaminação em latas de bebidas. CONIC SEMESP.

Souza, M. N. C., Ricardino, I. E. F., Silva Neto I. F. et al. (2020). Perfil de microrganismos presentes na superfície de latas de bebidas industrializadas com e sem o selo de proteção: uma revisão de literatura. Alimentos: Ciência, Tecnologia e Meio Ambiente, 1 (7), 1-10. 